\title{
How does occupational radiation exposure affect corneal endothelial cell density?
}

\author{
Mehmet Erol Can॰
}

Department of Ophthalmology, University of Health Sciences, Bursa Yüksek Ihtisas Traning and Research Hospital, Bursa, Turkey

DOI: $10.18621 /$ eurj.509803

\begin{abstract}
Objectives: To evalute the corneal endothelium ofradiology technicians.

Methods: The study included 35 radiology technicians (study group), and 34 healthy individuals as the control group. Central corneal thickness (CCT), Endothelial cell density (ECD), the coefficient of variation (CoV), and the percentage of hexagonal cells (Hexa) were measured using specular microscopy (Konan Medical Inc., Nishinomiya, Japan).

Results: The mean age of the study participants was $35.82 \pm 9.34$ years in the study group, and $37.82 \pm 8.40$ years in the control group ( $p=0.332)$. The mean ECD was $2740.63 \pm 249.92$ cells $/ \mathrm{mm} 2$ in the study group, and $2828.70 \pm 287.40$ in the control group $(p>0.05)$. The mean CoV was $44.34 \pm 6.78 \%$ in the study group, and $44.24 \pm 4.99 \%$ in the control group $(p>0.05)$. Hexa was determined as $44.97 \pm 7.98 \%$ in the study group, and $45.97 \pm 7.06 \%$ in the control group $(p>0.05)$. The mean CCT was $511.50 \pm 42.52$ in the study group, and $514.18 \pm 43.55$ in the control group $(p>0.05)$. The mean ECD, CoV, Hexa, and CCTvalues were not statistically significant $(p>0.05)$.

Conclusion: This study revealed that endothelial cell density, the coefficient of variation, and percentage of hexagonal cells (Hexa) were not statistically different between the radiology technicians and control group. Nevertheless, there is a need for more comprehensive, controlled studies with larger samples.
\end{abstract}

Keywords: Radiology technicians, endothelial cell density, specular microscope, occupational radiation

Received: January 8, 2019; Accepted: February 19, 2019; Published Online: February 22, 2019

$\mathbf{R}$ adiation can be defined as the movement of energythrough space [1]. Visible light, X-rays, gamma-rays, microwaves and radio waves are forms of radiation [1]. X-rays are a type of ionizing radiation which includes two sources; natural background radiation and medical exposure. The Sun (cosmic radiation), the Earth (mostly Radon gas) and from naturally radioactive substances in our body are natural background radiations [2]. Plain films, fluoroscopy and computed tomography are medical exposure radia- tions [3]. X-rays cross over the body and generate an image on film based on how many X-rays are absorbed and how many pass through [4]. However, Xrays passing through the body can damage the DNA, especially in radiation-sensitive tissues and organs. Lymphoid organs, bone marrow, blood, testes, ovaries, intestines, skin and other organs with epithelial cell lining (cornea, oral cavity, esophagus, rectum, bladder, vagina, uterine cervix, ureters, optic lens, stomach, growing cartilage, fine vasculature, and growing bone

Address for correspondence: Mehmet Erol Can, MD., University of Health Sciences, Bursa Yüksek Ihtisas Traning and Research Hospital, Mimar Sinan Mahallesi Emniyet Caddesi Polis Okulu Karşısı, Yıldırım, Bursa, Turkey

E-mail:drm.erolcan@gmail.com,Fax:009002242955000 
are radiosensitivity tissues and organs. Mature cartilage or bones, salivary glands, respiratory organs, kidneys, liver, pancreas, thyroid, adrenal and pituitary glands, muscle, brain, and the spinal cord are low radiosensitivity tissues and organs [5].

The cornea is avascular, transparent tissue which is located at the most anterior aspect of the eye [6]. The cornea has 6 layers; corneal epithelium, Bowman's layer, the corneal stroma, Descemet's membrane, Dua layer, and corneal endothelial cells $[6,7]$. The corneal epithelium acts as a natural barrier against radiation [8], and although the cornea blocks Ultraviolet $\mathrm{C}$ and $\mathrm{B}$, Ultraviolet A can penetrate full thickness cornea [8]. In the electromagnetic spectrum, $\mathrm{x}$-rays are very high frequency waves and carrying higher energy than ultraviolet rays, and therefore, X-rays can cause more cell damage than ultraviolet rays [1].

Corneal specular microscopy is a non-invasive technique used in morphological analysis of the corneal endothelial cell layer [9]. The corneal endothelial cell provides corneal clarity by regulating corneal hydration [10]. Unlike the corneal epithelium, cells have to migrate and change shape to fill endothelial defects, and corneal endothelial cells do not proliferate [10], but decrease with aging.

The main aim of this study was to investigate whether there were any changes in corneal endothelial cell parameters in radiology technicians compared with healthy subjects not exposed to occupational radiation.

\section{METHODS}

\section{Study Subjects}

This prospective, cross-sectional study investigated 35 radiology technicians and 34 healthy individualsas the control group. The study was performed in accordance with the Declaration of Helsinki. Approval for this human study was granted by the Local Ethics Committee of Bursa Yuksek Ihtisas Training and Research Hospital. All adult participants provided written informed consent to participate in the study.

\section{Examination Protocol and Study Measurements}

Each participant underwent a complete ophthalmological assessment, including best- corrected visual acuity (BCVA), slit-lamp biomicroscopy, and intra-ocular pressure (IOP).

Specular microscopy (Konan Medical Inc., Nishinomiya, Japan) was used to measure the corneal endothelial cells. Central corneal thickness (CCT), endothelial cell density (ECD), the coefficient of variation $(\mathrm{CoV})$, and percentage of hexagonal cells (Hexa) were measured using specular microscopy. The right eye of each participant was used for analysis. All measurements were taken by an experienced clinician (M.E.C.).

\section{Exclusion Criteria}

Ophthalmic exclusion criteria included patients with any history of orbital disease, a best corrected visual acuity (BCVA) worse than 20/20, a refractive error less than -4 diopters (D) or more than $+2 \mathrm{D}$, intraocular pressure (IOP) readings $>21 \mathrm{~mm} \mathrm{Hg}$, a history of uveitis, retinal disease, corneal disease, corneal or intraocular surgery, pregnancy, or any associated systemic disorders that might affect the eyes (e.g., uncontrolled diabetes, hypertension, or connective tissue diseases ).

\section{Statistical Analysis}

Statistical analysis was performed using the Statistical Package for the Social Sciences software version 20.0 (SPSS Inc., Chicago, IL, USA). Ocular parameter measurements of the right eyes were used for the analyses. For the continuous variables, the data were tested for normality using the KolmogorovSmirnov test. The Chi-square test was used to define variations in categorical variables. The Independent $t$ test was used to assess differences in scale variables and Pearson correlation analysis to evaluate correlations between each pair of measurements. All the results were stated as mean \pm standard deviation(SD). A value of $p<0.05$ was considered statistically significant.

\section{RESULTS}

\section{Demographic Characteristics}

The study group comprised $16(46 \%)$ females and $19(54 \%)$ males, and the control group comprised 22 $(65 \%)$ females and $12(35 \%)$ males $(p=0.148)$. The mean age was $35.82 \pm 9.34$ years (range, 22-53 years) 
Table 1. Patient demographics and characteristics of each group

\begin{tabular}{|c|c|c|c|}
\hline & $\begin{array}{l}\text { Study group } \\
\quad(\mathbf{n}=\mathbf{3 5})\end{array}$ & $\begin{array}{l}\text { Control group } \\
\quad(n=34)\end{array}$ & $p$ value $^{\mathrm{a}}$ \\
\hline \multicolumn{4}{|l|}{ Age (years) } \\
\hline Mean \pm SD & $35.82 \pm 9.34$ & $37.82 \pm 8.40$ & 0.148 \\
\hline Range & $22-53$ & $21-56$ & \\
\hline \multicolumn{4}{|l|}{ Sex } \\
\hline Female & $16(46 \%)$ & $22(65 \%)$ & $0.332^{\mathrm{b}}$ \\
\hline Male & $19(54 \%)$ & $12(35 \%)$ & \\
\hline \multicolumn{4}{|c|}{ Working in radiology (years) } \\
\hline Mean \pm SD & $12.56 \pm 7.85$ & NA & \\
\hline Range & $4-24$ & NA & \\
\hline
\end{tabular}

NA: Not applicable SD: Standard deviation, ${ }^{a}$ Independent Samples $t$ test, ${ }^{b}$ Chi-square test.

in the study group and $37.82 \pm 8.40$ years (range, 21 56 years) in the control group $(p=0.332)$.

The mean values of age, age gender distribution, and working in radiology (years) in the study group and the control group are summarized in Table 1.

\section{Results of Corneal Specular Microscopy}

The mean ECD was $2740.63 \pm 249.92$ in the study group, and $2826.70 \pm 287.40$ in the control group ( $p>$ 0.05). The mean $\mathrm{CoV}$ was $44.34 \pm 6.78$ in the study group, and $44.24 \pm 4.99$ in the control group ( $p>$ $0.05)$. The mean Hexa was $44.97 \pm 7.98$ in the study group, and $45.97 \pm 7.06$ in the control group $(p>$ 0.05). The mean CCT was $511.40 \pm 42.52$ in the study group, and $514.18 \pm 43.55$ in the control group ( $p>$ $0.05)$. The corneal specular microscopy measurements of both the control and study groups are summarized in Table 2. The ECD, CoV, Hexa, and CCT values were not correlated with the time working in radiology (years) in the study group $(p>0.05)$.

\section{DISCUSSION}

In this study, the corneal cell features of the eye were evaluated in radiology technicians. The results demonstrated no difference between radiology technicians and the healthy control group in respect of ECD, CoV, Hexa, and CCT values.

$\mathrm{X}$-rays are a type of radiation with shorter wavelengths, higher frequency and energy in the electromagnetic spectrum [1]. X-ray helps to create images of the inside of the body. This image is formed according to different amounts of radiation from different tissue. Hard tissues absorb x-rays the most, so appear white. Soft tissues absorb less, and appear gray or black. X-rays can damage the DNA either directly or through the production of free radicals, and this can ultimately cause cancer. This side-effect of DNA damage is seen in radiosensitive cells in particular [5]. Radiosensitivity is related to the susceptibility of cells. The corneal epithelium and lens

Table 2. Comparison of the corneal specular microscopy measurements in the study and control groups

\begin{tabular}{cccc}
\hline & Study group & Control group & $\boldsymbol{p ~ v a l u e ~}^{\mathbf{a}}$ \\
\hline ECD & $2740.63 \pm 249.92$ & $2826.70 \pm 287.40$ & 0.191 \\
CoV & $44.34 \pm 6.78$ & $44.24 \pm 4.99$ & 0.945 \\
Hexa & $44.97 \pm 7.98$ & $45.97 \pm 7.06$ & 0.588 \\
CCT & $511.40 \pm 42.52$ & $514.18 \pm 43.55$ & 0.791 \\
\hline
\end{tabular}

Data are shown as mean \pm standard deviation. ${ }^{a}$ The Independent $t$ test, $\mathrm{ECD}=$ Endothelial cell density, $\mathrm{CoV}=$ Coefficient of variation, Hexa $=$ percentage of hexagonal cells, $\mathrm{CCT}=$ Central corneal thickness 
epithelium in the eye are more radiosensivite than other parts of the eye. Chalupecky first described the effects of ionizing radiation on the eye [11], while Birch-Hirschpeld identified the first case of radiation cataract [12] and Rohrschneider described the radiosensitivity of ocular parts, with the lens determined as the most sensitive tissue [13]. The conjunctiva, cornea, uvea, retina, and the sclera are less sensitive than the lens [14].

Damage to the conjunctiva, cornea, lens, ocular adnexa and retina has been reported in literature. The lens is an avascular structure located in the anterior segment of the eye, which is one of the most radiosensitive tissues in the human body. As a result of ionising radiation, the lens epithelium is damaged, resulting in abnormal lens fibres, followed by loss of transparency and ultimately a cataract is formed. Cataracts are a most frequently reported finding in literature whicch can develop in one or both eyes. Common symptoms are blurred vision, dull colors, glare, double vision, and changes in prescription eye wear. Cataract formation is not related to high dosage $\mathrm{X}$-rays but is correlated to deterministic radiationinduced effects [15].

The cornea is the anterior transparent segment of the eye, which allows the transmission of light to the lens. The cornea and lens provide the refracting power of the eye and if they are damaged for any reason, vision defects will occur. The corneal epithelium is more radiosensitive than other parts of the cornea. The cornea blocks a significant proportion of ultraviolet radiation (UVR) with the corneal epithelium absorbing $96 \%$ of UVB but only $4 \%$ of UVA [8]. UVR causes corneal epithelium diseases such as pterygium, photokeratitis, climatic droplet keratopathy and ocular surface squamous neoplasia [8]. UVR can also cause corneal endothelial changes, cataract and retinal degeneration [16]. UVR has longer wavelengths, lower frequency and energy in the electromagnetic spectrum than X-rays, which are more harmful than UVR.

Another condition associated with ionizing radiation is radiation retinopathy, which can develop during radiotherapy. The $\mathrm{X}$-rays affect the endothelial cells and capillary-like network formation in the retinal vessels. The pathogenesis of radiation retinopathy is related to the total radiation dosage, fraction size, concomitant chemotherapy, and pre- existing vascular disorders. These processes are associated with progressive time and dose-dependent reactions. The clinical presentation of radiation retinopathy includesmicroaneurysms, cotton wool spots, capillary dilation, telangectasia, capillary closure, retinal oedema, optic disc neovascularization, vitreous haemorrhage, and retinal detachment [17].

To the best of our knowledge, there have been noprevious studiesof corneal endothelial cell damage from X-rays. Therefore, this study is the first to describe an association between corneal endothelial cell morphology and occupational radiation exposure. According to the results, corneal endothelial cell morphology is not changed in radiology technicians.

In human body rapidly dividing, undifferentiated cells of tissues that are most susceptible to radiation effects. Corneal endothelial cells are not proliferating. This could be one reason for why corneal endothelial cells numbers and morphology are not diffirent in radiology technicians. However, the ECD was found to be lower in the radiology technicians than in the control group but not to a statistically significant level $(p=0.191)$. The CoV, Hexa, and CCT values were not statistically significant $(p>0.05)$. Fish et al. [18] studied the relationships of ocular pathology ininterventional pain physicians and reported that cataract formation was related to radiation-induced effects.

Chodick et al. [19] investigated the association between cataract and exposure to low doses of ionizing radiation in radiology technicians. That prospective cohort study was conducted over 20 years with 66,379 participants and as a result of the study, 2,382 cataracts and 647 cataract surgeries were reported.

To the best of our knowledge, this is the first study in literature to have examined corneal endothelial cell morphology in radiation technicians.

As there is a risk that other ocular pathologies are related tooccupational radiation exposure, further investigativestudies are required to define these. It can be strongly recommended that all personnel exposed to occupational radiation have routine eye examinations. Further research with greater patient numbers is required to further understand the association between corneal endothelial morphology and occupational radiation exposure. 


\section{CONCLUSION}

The results of this study showed that corneal endothelial morphology was not changed in the radiology technicians. There is a need for further studies to demonstrate corneal effects associated with $\mathrm{X}$-rays.

\section{Conflict of interest}

The authors disclosed no conflict of interest during the preparation or publication of this manuscript.

\section{Financing}

The authors disclosed that they did not receive any grant during conduction or writing of this study.

\section{REFERENCES}

[1] Manickavasagan A, Jayasuriya H. Imaging with Electromagnetic Spectrum: Applications in Food and Agriculture.Springer Berlin Heidelberg; 2014.

[2] Ramachandran T V. Background radiation, people and the environment. Int J Radiat Res2011;9:63-76.

[3] Mazrani W, McHugh K, Marsden PJ. The radiation burden of radiological investigations. Arch Dis Child 2007;92:1127-31.

[4] Reed AB. The history of radiation use in medicine. J Vasc Surg 2011;53:3-5.

[5] Rubin P, Casarett GW. Clinical radiation pathology as applied to curative radiotherapy. Cancer1968;22:767-78.

[6] DelMonte DW, Kim T. Anatomy and physiology of the cornea. J Cataract Refract Surg2011;37:588-98.

[7] Dua HS, Said DG. Clinical evidence of the pre-Descemets layer (Dua's layer) in corneal pathology. Eye (Lond)
2016;30:1144-5.

[8] Delic NC, Lyons JG, Di Girolamo N, Halliday GM. Damaging Effects of Ultraviolet Radiation on the Cornea. Photochem Photobiol 2017;93:920-9.

[9] McCarey BE, Edelhauser HF, Lynn MJ. Review of corneal endothelial specular microscopy for FDA clinical trials of refractive procedures, surgical devices, and new intraocular drugs and solutions. Cornea 2008;27:1-16.

[10] Bourne WM. Biology of the corneal endothelium in health and disease. Eye 2003;17:912-8.

[11] Chalupecky H. Ueber die Wirkung der Rontgenstrahlen auf das Auge und die Haut. Zentralbl F Prakt Augenh 1897;21:886.

[12] Von Gassmann H, wurden nach Einwirkung F. Zur Wirkung der Röntgenstrahlen auf das menschliche Auge. Klin Monbl Augenheilkd. Verlag von Ferdinand Enke; 1908;46:129.

[13] Rohrschneider W. Experimentelle Untersuchungen über die Veränderungen normaler Augengewebe nach Röntgenbestrahlung. Albr von Graefes Arch für Ophthalmol 1929;122:282-98.

[14] Alberti WE, Richard G, Sagerman RH, editors. Age-Related Macular Degeneration Berlin, Heidelberg: Springer Berlin Heidelberg; 2001.

[15] The 2007 Recommendations of the International Commission on Radiological Protection. ICRP publication 103. Ann ICRP 2007;37:1-332.

[16] Van Kuijk FJ. Effects of ultraviolet light on the eye: role of protective glasses. Environ Health Perspect 1991;96:177-84.

[17] Gupta A, Dhawahir-Scala F, Smith A, Young L, Charles S. Radiation retinopathy: case report and review. BMC Ophthalmol 2007;7:6.

[18] Fish DE, Kim A, Ornelas C, Song S, Pangarkar S. The risk of radiation exposure to the eyes of the interventional pain physician. Radiol Res Pract 2011;2011:609537.

[19] Chodick G, Bekiroglu N, Hauptmann M, Alexander BH, Freedman DM, Doody MM, et al. Risk of cataract after exposure to low doses of ionizing radiation: a 20-year prospective cohort study among US radiologic technologists. Am J Epidemiol 2008;168:620-31. 